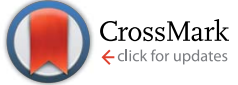

Cite this: RSC Adv., 2016, 6, 82174

Received 6th July 2016

Accepted 15th August 2016

DOI: 10.1039/c6ra17284a

www.rsc.org/advances

\section{Graphene oxide polypiperazine-amide nanofiltration membrane for improving flux and anti-fouling in water purification}

\begin{abstract}
Jin Wang, ${ }^{a}$ Changwei Zhao, ${ }^{\mathrm{b}}$ Tao Wang, ${ }^{\mathrm{a}}$ Zhen $\mathrm{Wu}^{\mathrm{c}}$ Xiang $\mathrm{Li}^{\mathrm{a}}$ and Jiding $\mathrm{Li}^{\star \mathrm{a}}$
In this study, a facile polypiperazine-amide (PPA) composite nanofiltration (NF) membrane with nanomaterial graphene oxide (GO) incorporated into a polyamide (PA) layer for high water flux and anti-fouling was fabricated by interfacial polymerization (IP). The chemical composition, structure and surface properties of the fabricated PPA/GO and PPA composite NF membranes were characterized by FTIR, XPS, FE-SEM, AFM, zeta-potential and contact angle measurements. The separation properties and anti-fouling ability of the PPA/GO NF membrane were investigated and discussed. The experimental results indicated that the water flux of the PPA/GO (300 mg L $\left.{ }^{-1} \mathrm{GO}\right)$ membrane increased from $66\left(\mathrm{~L} \mathrm{~m}^{-2} \mathrm{~h}^{-1}\right)$ to $87.6\left(\mathrm{~L} \mathrm{~m}^{-2} \mathrm{~h}^{-1}\right)$ under the operating pressure of $0.6 \mathrm{MPa}$, almost 1.4 times that of the PPA (without GO) membrane. However, the high salt rejection was still retained in the order of $\mathrm{Na}_{2} \mathrm{SO}_{4}(98.2 \%)>\mathrm{MgSO}_{4}(96.5 \%)>\mathrm{NaCl}$ $(56.8 \%)>\mathrm{MgCl}_{2}$ (50.5\%). An anti-fouling test revealed that the PPA/GO membrane had excellent antifouling properties due to the enhanced hydrophilicity and decreased roughness induced by the GO nanosheets. Thus, the PPA/GO membrane can be efficiently and endurably applied in water purification.
\end{abstract}

\section{Introduction}

The nanofiltration (NF) membrane process is a pressureactuated separation technique that lies between ultrafiltration (UF) and reverse osmosis (RO). Comparing with RO, the major advantages of NF include its greater water permeation and lower operating pressure. In the separation process, by means of a primary separation mechanism of size exclusion or Donnan exclusion, an NF membrane can efficiently remove many pollutants such as viruses, bacteria, suspended solids, multivalent ions, heavy metals and molecular weights of organic molecules between 200 and 500 Da., ${ }^{1,2}$ Nowadays, NF has been widely used in many fields of desalination, ${ }^{3}$ water separation and purification, ${ }^{4}$ dye removal, ${ }^{5}$ recovery of organic solvents ${ }^{6}$ etc.

In general, the selective layer is the main structure of the most commercial nanofiltration membrane, which is primarily prepared by interfacial polymerization (IP) occurred on the two immiscible phase's interface..$^{7-9}$ However, the fact that it fouls easily at long-time operation seriously hinders it from being applied widely. ${ }^{10}$ As many foulants are naturally hydrophobic, ${ }^{11}$ it is believed that increase of the membrane surface hydrophilicity can overcome these problems. In this respect, the

${ }^{a}$ The State Key Laboratory of Chemical Engineering, Department of Chemical Engineering, Tsinghua University, Beijing 100084, China.E-mail: lijiding@tsinghua. edu.cn; Fax: 86-10-62773234; Tel: 86-10-62782432

${ }^{b}$ Research Center for Eco-Environmental Sciences, Chinese Academy of Sciences, Beijing 100085, China

'Ordos Redbud Innovation Institute, Ordos 017000, China researchers had made efforts to find the proper surface modification methods to enhance the anti-fouling property of membrane and improve its water flux at the same time. ${ }^{12}$

On this issue, different strategies have been carried out to enhance the membrane surface properties. In general, blending hydrophilic materials ${ }^{\mathbf{1 3}}$ or adding nanomaterials ${ }^{\mathbf{1 4 - 1 6}}$ into casting solution, coating the hydrophilic segments onto membranes surface, ${ }^{\mathbf{1 7}}$ chemical modification ${ }^{\mathbf{1 8}}$ and plasma polymerization ${ }^{\mathbf{1 9 - 2 1}}$ etc. are the main modified approaches. In recent years, incorporating with inorganic nanomaterials to prepare composite membrane has aroused great interest due to its expedite operation and mild conditions. ${ }^{22}$ Many carbon nanomaterials such as GO, carbon nanotube and so on have been widely applied to modify polyamide NF membranes. ${ }^{23-31}$ Among different nanomaterials, GO has attracted the most attention owing to its numerous hydrophilic groups and high hydrophilicity, ${ }^{32,33}$ and it can be evenly dispersed in water. $^{34}$ Therefore, incorporation of GO into membrane has been applied to enhance the water permeation and anti-fouling of membrane. ${ }^{35,36}$ For instance, Zhang et al. ${ }^{37}$ prepared the high anti-fouling polyvinylidene fluoride (PVDF) UF membranes via blending GO into the matrix membrane. In order to suppress the membrane fouling, Lee et $a{ }^{38}{ }^{38}$ regulated the structure and surface charge of polysulfone (Psf) UF membrane by incorporating GO nano-materials. Wang et $a l .{ }^{39}$ reported nanohybrid membrane through self-assembly of GO for nanofiltration and pervaporation that had excellent salts rejection, dye removal capacity and pervaporation dehydration properties. Moreover, GO modified hydrophilic polyamide (PA) nanofiltration 
membrane via IP with $m$-phenylenediamine (MPD) and trimesoyl chloride (TMC) for removing the natural organic molecule was fabricated by Xia et al. ${ }^{10}$ Nowadays, the way of modifying the selective layer of polyamide NF membrane by GO usually use MPD and TMC as the monomers for IP. However, fabrication of polypiperazine-amide nanofiltration membrane by dispersion of GO in piperazine (PIP) aqueous reacting with TMC organic phase for improving water flux and anti-fouling property is rarely reported.

Therefore, a novel high water flux, salts rejection and excellent anti-fouling property of PPA/GO composite NF membrane was fabricated by IP in this study. ATR-FTIR, XPS, FE-SEM, AFM, zeta-potential and water contact angle measurement were used to characterize the chemical composition, structure and surface property of the PPA/GO composite NF membrane. The separation performance for different salts and the anti-fouling property of the PPA/GO and PPA membrane were investigated.

\section{Materials and methods}

\subsection{Materials}

Polyether sulfone (PES) ultrafiltration (UF) membranes supplied by Advanced Membrane Technology INC Co. Ltd (China) were

Table 1 The physical properties of the PES substrate membrane

\begin{tabular}{lllll}
\hline $\begin{array}{l}\text { Membrane } \\
\text { materials }\end{array}$ & $\begin{array}{l}\text { Molecular } \\
\text { weight } \\
\text { cut-off (MWCO) }\end{array}$ & $\begin{array}{l}\text { Water flux } \\
\left(\mathrm{L} \mathrm{m}^{-2}\right. \\
\left.\mathrm{h}^{-1} \mathrm{bar}^{-1}\right)\end{array}$ & $\begin{array}{l}\text { Mean pore } \\
\text { size }(\mathrm{nm})\end{array}$ & $\begin{array}{l}\text { Contact } \\
\text { angle }\left(^{\circ}\right)\end{array}$ \\
\hline PES & 30000 & 73 & $15 \pm 0.6$ & $69 \pm 3.3$
\end{tabular}

used as substrates. The PES membranes were stored in fresh deionized water before using and its molecular weight cut-off, pure water permeation, mean pore size and water contact angle were listed in Table 1. Graphene oxide (GO) was purchased from Shanxi carbon technology Chemical Co., Ltd (China). The GO nanosheets were characterized by SEM, TEM and AFM as shown in Fig. 1. The type of wrinkles and transparency structure of GO was found in Fig. 1(a) and (b), respectively. The AFM image of GO in Fig. 1(c) showed its irregular shape and horizontal direction size. The thickness of GO sheets was approximate 1.8 $\mathrm{nm}$ as shown in Fig. 1(d), which suggested that the dispersion of GO contained 3-4 layers in this work. The IP reaction monomers of piperazine (PIP) and trimesoyl chloride (TMC) were provided by Sigma-Aldrich (USA). $n$-Hexane organic solvent was purchased from Beijing chemical works (China). Calcium chloride $\left(\mathrm{CaCl}_{2}\right)$, sodium sulfate $\left(\mathrm{Na}_{2} \mathrm{SO}_{4}\right)$, magnesium sulfate $\left(\mathrm{MgSO}_{4}\right)$, sodium chloride $(\mathrm{NaCl})$, magnesium chloride $\left(\mathrm{MgCl}_{2}\right)$ (analytical grade, $>99 \%$ ), humic acid (HA) and bovine serum albumin (BSA) were supplied by Sinopharm Chemical Reagent Co. Ltd (Shanghai, China). Glucose, saccharose, raffinose and $\alpha$-cyclodextrin were purchased from Sigma-Aldrich (USA). The properties of the neutral solutes were listed in Table $2{ }^{40}$ High-purity deionized water (DI) with an electrical resistivity of $4.5 \mathrm{M} \Omega \mathrm{cm}$ was used in this experiments. All chemicals were directly used without further purification.

\subsection{Preparation of PPA/GO composite nanofiltration membrane}

PPA/GO composite NF membranes were fabricated through IP. The preparation process was shown in Fig. 2. The PES membranes were immersed in DI water for $24 \mathrm{~h}$ before using.
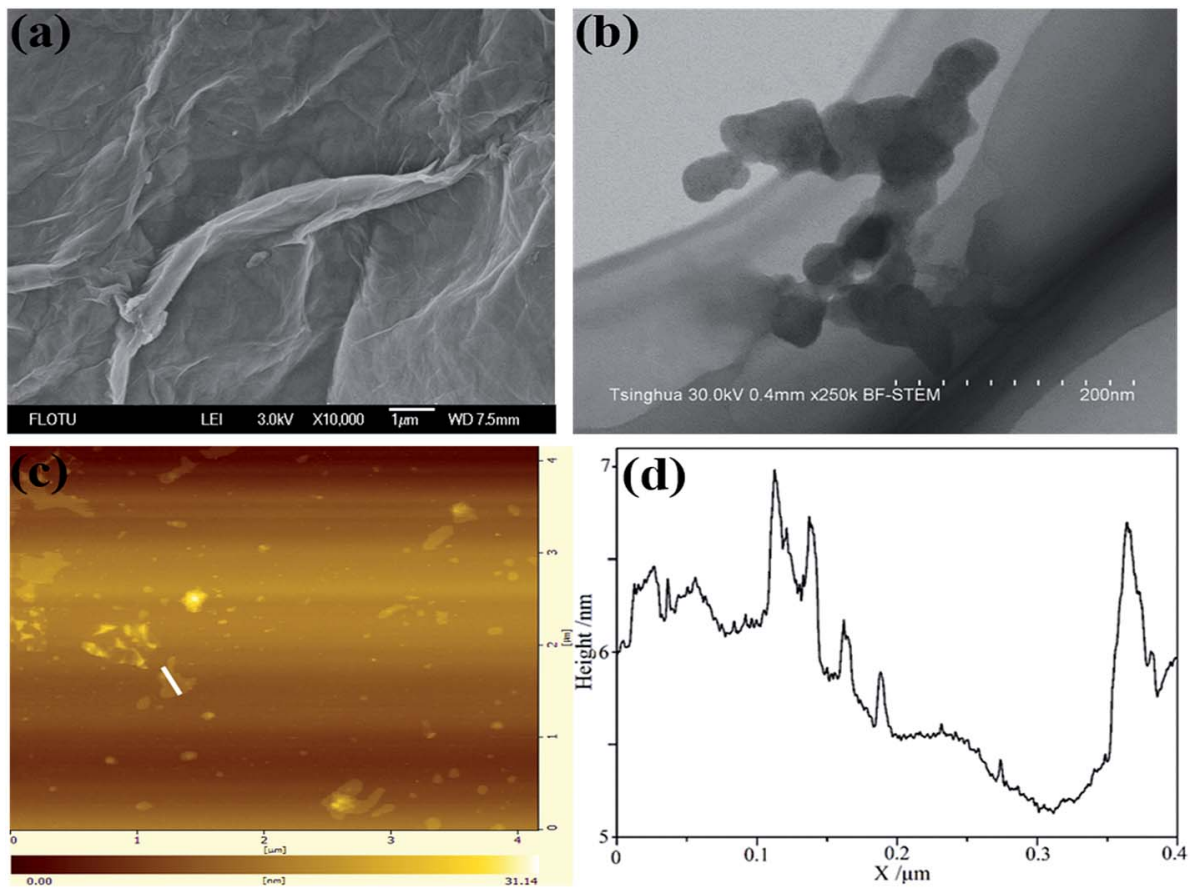

Fig. 1 (a) SEM image of GO; (b) TEM image of GO; (c) AFM image of GO; (d) height profiles of GO sheets. 
Table 2 Diffusivities and Stokes radii of neutral solutes in aqueous solutions (at $25^{\circ} \mathrm{C}$ )

\begin{tabular}{llll}
\hline Solute & $M_{\mathrm{w}}\left(\mathrm{g} \mathrm{mol}^{-1}\right)$ & $D_{\mathrm{s}}\left(\times 10^{-9} \mathrm{~m}^{2} \mathrm{~s}^{-1}\right)$ & $r_{\mathrm{s}}(\mathrm{nm})$ \\
\hline Glucose & 180 & 0.67 & 0.365 \\
Saccharose & 342 & 0.52 & 0.471 \\
Raffinose & 504 & 0.42 & 0.584 \\
$\alpha$-Cyclodextrin & 972 & 0.35 & 0.701
\end{tabular}

The wet PES membranes were hung in air to slightly dry for 2 min and then installed in self-made facility for keeping the PES membrane surface upward. To begin with, the aqueous phase solution containing PIP and GO were poured on the PES surface and maintained for $120 \mathrm{~s}$, then the aqueous solution were removed from the membrane surface with the help of soft rubber. Whereafter, $n$-hexane organic solution contained 0.1 (w/ v)\% TMC were introduced onto the membrane surface to generate the IP reaction for a certain time, and then organic solution were poured away from the membrane surface. Subsequently, the prepared PPA/GO nanofiltration membranes were heated treatment at $80{ }^{\circ} \mathrm{C}$ for $5 \mathrm{~min}$ to make sure the further polymerization. Finally, the heat treatment membranes were sufficiently washed and then stored in DI water. The different GO contents in aqueous solution were investigated to ensure the optimal conditions. Table 3 listed the composition and fabrication conditions of the different PPA/GO composite nanofiltration membranes via IP.

\subsection{Characterization of the PPA/GO composite nanofiltration membranes}

2.3.1 Surface chemistry. The surface functional groups of the PPA/GO and PPA membranes were analyzed by Fourier Transform Infrared Spectroscopy (ATR-FTIR, Nicolet IR 560). Surface elemental composition changes were characterized by
Table 3 The PPA/GO composite membrane prepared under different conditions $^{a}$

\begin{tabular}{lllll}
\hline Membrane ID & $\begin{array}{l}\text { GO content } \\
\left(\mathrm{mg} \mathrm{L}^{-1}\right)\end{array}$ & $\begin{array}{l}\text { PIP content } \\
(\mathrm{wt} \%)\end{array}$ & $\begin{array}{l}\text { TMC content } \\
(\mathrm{w} / \mathrm{v} \%)\end{array}$ & $\begin{array}{l}\text { IP time } \\
(\mathrm{s})\end{array}$ \\
\hline M0 & 0 & 1.5 & 0.1 & 30 \\
M1 & 100 & 1.5 & 0.1 & 30 \\
M2 & 200 & 1.5 & 0.1 & 30 \\
M3 & 300 & 1.5 & 0.1 & 30 \\
M4 & 400 & 1.5 & 0.1 & 30
\end{tabular}

${ }^{a}$ Other membranes preparation conditions: $\mathrm{pH}$ of aqueous phase $=10$, curing temperature $=80^{\circ} \mathrm{C}$, curing time $=5 \mathrm{~min}$.

X-ray photoelectron spectroscopy (XPS, PHI Quantera SXM, ULVAC-PHI).

2.3.2 Morphological structure. The morphological structure of the fabricated NF membranes were monitored on the field emission scanning electron microscopy (FE-SEM, Hitachi S-5500, Japan). The surface roughness of the $10 \mu \mathrm{m} \times 10 \mu \mathrm{m}$ area membranes were also detected by atomic force microscopy (AFM, SPM-970, Shimadzu).

2.3.3 Surface charge. The surface charge property of the composite NF membranes were investigated by zeta potential analysis meter (Anton Paar, Austria). The membrane samples were put into measuring cell containing $0.001 \mathrm{~mol} \mathrm{~L}^{-1}$ potassium chloride solution with $\mathrm{pH}$ values from 3 to 11 at $25{ }^{\circ} \mathrm{C}$.

2.3.4 Contact angles. The contact angles of the membranes surface were characterized by contact angle meter (OCA 15 EC, Dataphysics Instruments, Germany). In this paper, the water contact angles were the ten average value angles on the different membrane surface locations.

\subsection{Membrane performance test}

The separation performance of the prepared NF membranes was measured using a cross-flow filtration test unit (CEPA CFII,

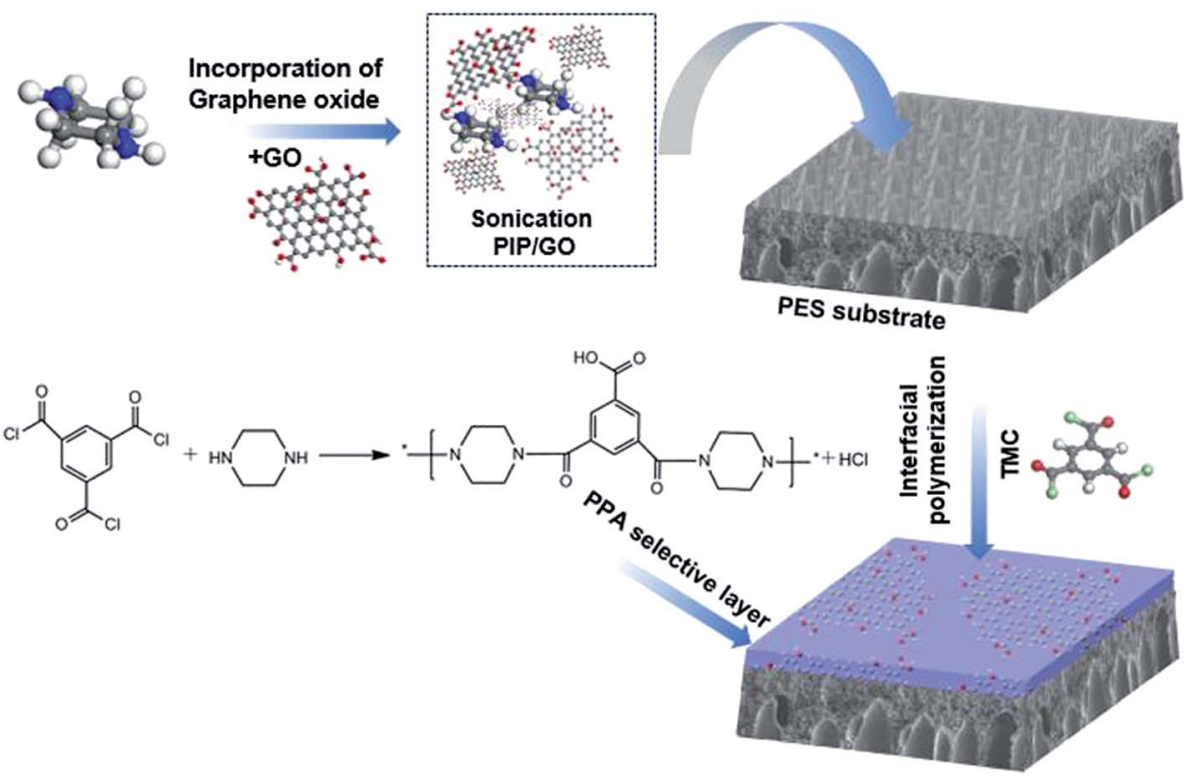

Fig. 2 Conceptual illustration of PPA/GO composite nanofiltration membranes. 
GE Osmonics, USA) as shown in Fig. 3. The effective membrane area $14.6 \mathrm{~cm} \times 9.5 \mathrm{~cm}$ was used in this study, and all membranes performance tests were operated at room temperature. In order to achieve a stable water flux, the NF membranes were pre-pressurized under a pressure of 1.0 MPa before collecting water volume. The pure water fluxes of NF membrane were calculated by eqn (1):

$$
F=\frac{J}{S \times t}
$$

where $J(\mathrm{~L})$ is the permeate water volume; $S\left(\mathrm{~m}^{2}\right)$ is the effective membrane area; and $t(\mathrm{~h})$ is the water permeation time.

To measure the salts rejection of membrane, four different inorganic salts by dissolving $\mathrm{Na}_{2} \mathrm{SO}_{4}, \mathrm{MgSO}_{4}, \mathrm{NaCl}$ and $\mathrm{MgCl}_{2}$ in DI water at a concentration of $2000 \mathrm{mg} \mathrm{L}^{-1}$ respectively were used in this work. The solute rejection $R$, was calculated by eqn (2):

$$
R=\left(1-\frac{c_{\mathrm{p}}}{c_{\mathrm{f}}}\right) \times 100 \%
$$

where $c_{\mathrm{p}}$ and $c_{\mathrm{f}}$ are the permeate and feed solutions concentrations, respectively.

\subsection{Mean effective pore size and pore size distribution of the PPA/GO membrane}

The mean effective pore size, pore size distribution and the molecular weight cut-off (MWCO) of the PPA/GO NF membrane were obtained by the solute transport method. ${ }^{\mathbf{4 1 , 4 2}}$ Different neutral solutions by dissolving glucose, saccharose, raffinose, and $\alpha$-cyclodextrin in DI water at a concentration of $200 \mathrm{mg} \mathrm{L}^{-1}$ respectively were used in this work. The solute rejection was described to the function of solute size via eqn (3) and (4): ${ }^{43}$

$$
\begin{gathered}
R_{\mathrm{T}}=1-\frac{c_{\mathrm{p}}}{c_{\mathrm{f}}}=\operatorname{erf}(y)=\frac{1}{\sqrt{2 \pi}} \int_{-\infty}^{y} \mathrm{e}^{-\frac{u^{2}}{2}} \mathrm{~d} u \\
y=\frac{\ln r_{\mathrm{s}}-\ln \mu_{\mathrm{s}}}{\ln \sigma_{\mathrm{g}}}
\end{gathered}
$$

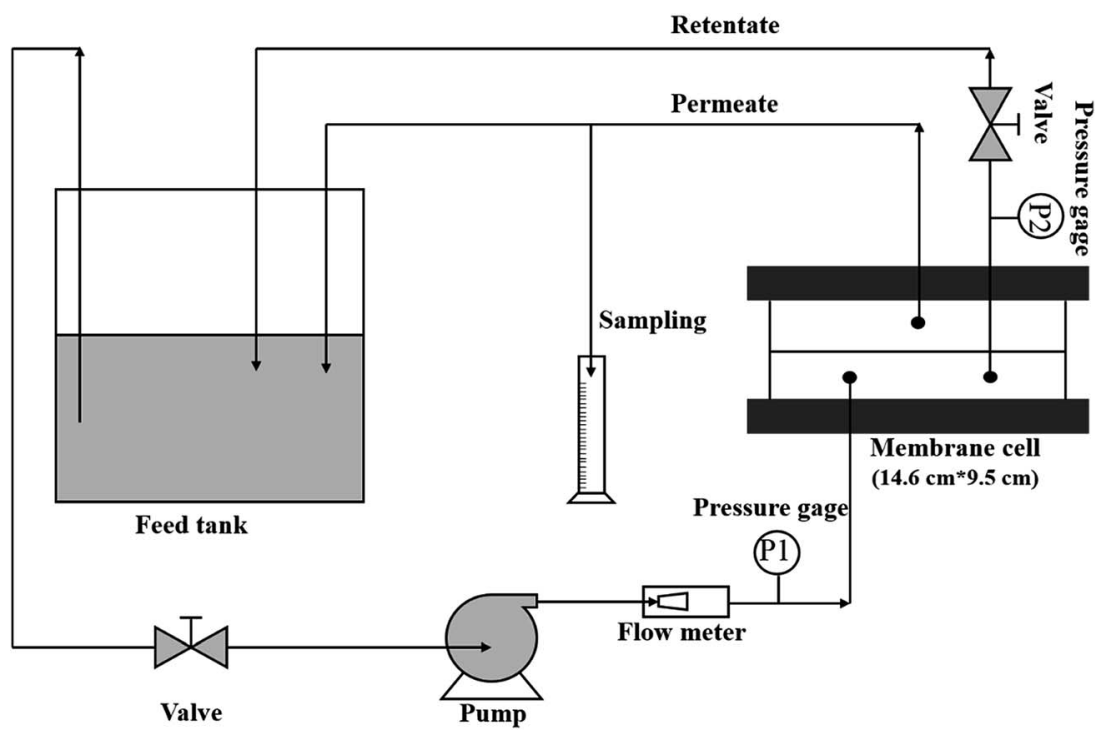

where $R_{\mathrm{T}}$ is the solute rejection; $c_{\mathrm{p}}$ and $c_{\mathrm{f}}$ are the permeate and feed neutral solutions concentrations, respectively; $r_{\mathrm{s}}$ is the solute radius; $\mu_{\mathrm{s}}$ is the geometric mean radius at $R_{\mathrm{T}}=50 \% ; \sigma_{\mathrm{g}}$ is the geometric standard deviation of $\mu_{\mathrm{s}}$, which is the ratio of $r_{\mathrm{s}}$ at $R_{\mathrm{T}}=84.13 \%$ and $r_{\mathrm{s}}$ at $R_{\mathrm{T}}=50 \%$.

The pore size distribution of the membrane was measured by the following probability density function of eqn (5):

$$
\frac{\mathrm{d} R\left(d_{\mathrm{p}}\right)}{\mathrm{d}\left(d_{\mathrm{p}}\right)}=\frac{1}{d_{\mathrm{p}} \ln \sigma_{\mathrm{p}} \sqrt{2 \pi}} \exp \left[-\frac{\left(\ln d_{\mathrm{p}}-\ln \mu_{\mathrm{p}}\right)^{2}}{2\left(\ln \sigma_{\mathrm{p}}\right)^{2}}\right]
$$

where $d_{\mathrm{p}}$ is the effective pore radius; the mean effective pore radius $\mu_{\mathrm{p}}$ and geometric standard deviation $\sigma_{\mathrm{p}}$ are considered to be same as $\mu_{\mathrm{s}}$ and $\sigma_{\mathrm{g}}$, respectively.

The relationship between Stokes radius, $r_{\mathrm{s}}(\mathrm{nm})$ and molecular weight, $M_{\mathrm{w}}\left(\mathrm{g} \mathrm{mol}{ }^{-1}\right)$ of neutral solutes (Table 2 ) could be described by eqn (6): ${ }^{44}$

$$
\log r_{\mathrm{s}}=-1.326+0.396 \log M_{\mathrm{w}}
$$

\subsection{Anti-fouling testing}

The concentration of $200 \mathrm{mg} \mathrm{L}^{-1}$ BSA and $200 \mathrm{mg} \mathrm{L}^{-1} \mathrm{HA}$ with the help of $20 \mathrm{mg} \mathrm{L}^{-1}$ calcium chloride solutions as foulants ${ }^{45-49}$ were used to test the anti-fouling property of the PPA/GO composite NF membrane. The permeate fluxes were obtained with variation of time.

\section{Results and discussion}

\subsection{Surface chemistry}

The surface chemical structures of M0 (without GO) and M3 (with GO) membranes were detected by ATR-FTIR as shown in Fig. 4(a). For the spectrum of M0 membrane, the peak at around $1642 \mathrm{~m}^{-1}$ had been seen clearly, which was corresponded to the carbonyl stretching vibration of amide-I. The peaks at 1540 $\mathrm{cm}^{-1}$ and $1520 \mathrm{~cm}^{-1}$ were the amide-II bands ascribed to the

Fig. 3 Schematic diagram of the cross-flow filtration test unit. 
$\mathrm{N}-\mathrm{H}$ and $\mathrm{C}-\mathrm{N}$ stretching vibrations. ${ }^{49}$ Compared with $\mathrm{M} 0$ membrane, the enhancement peak at $1642 \mathrm{~cm}^{-1}$ was observed in M3 membrane, which was attributed to the reaction of carboxyl in GO and amino in PIP to form the extra amide linkages. ${ }^{\mathbf{4 9 , 5 0}}$ Thus, the interaction of GO with PIP and TMC may be described in Fig. 4(b). It implied that the $-\mathrm{OH}$ and $-\mathrm{COOH}$
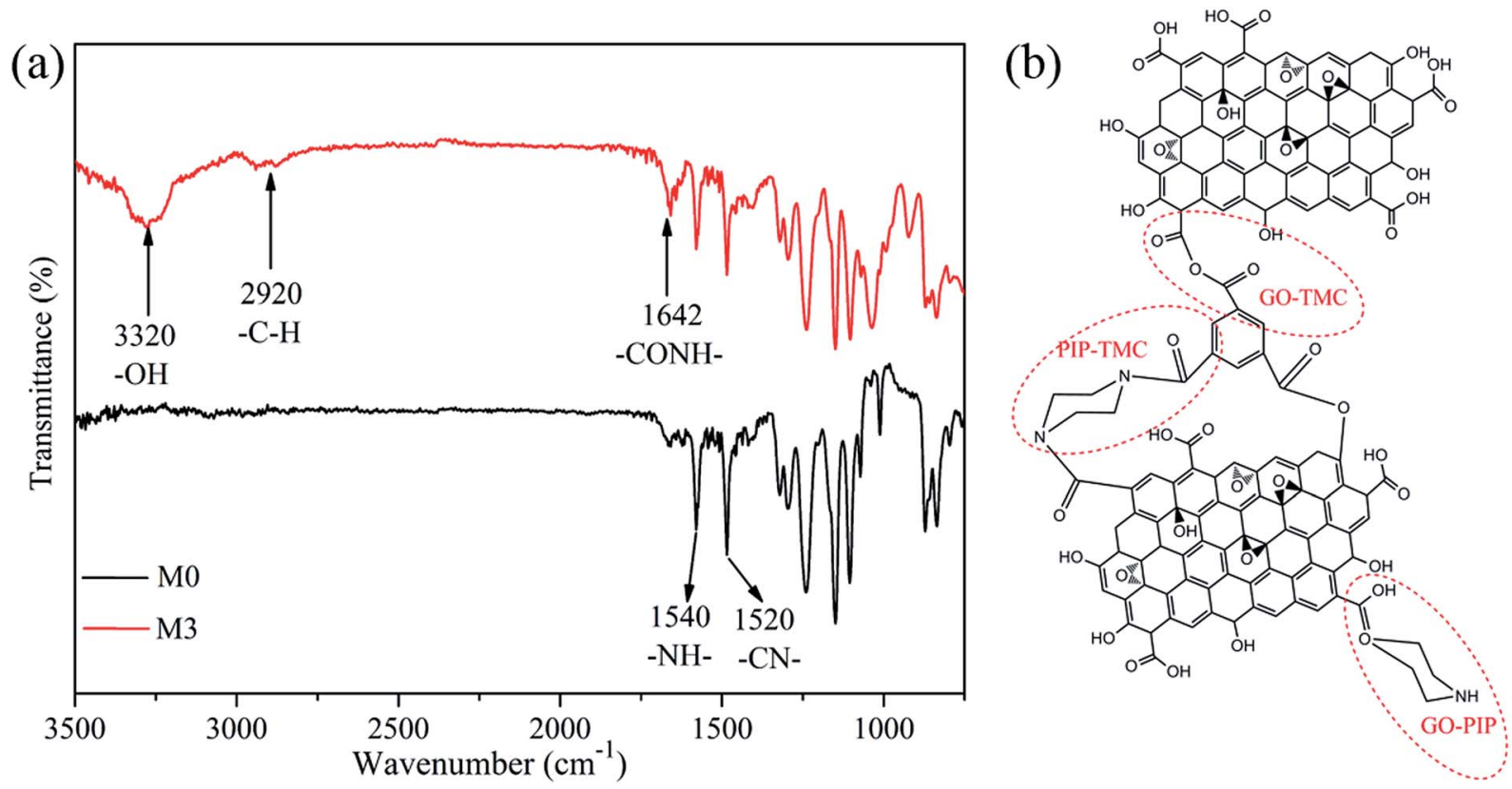

Fig. 4 (a) FTIR spectra of MO and M3; (b) interaction of GO with PIP and TMC.
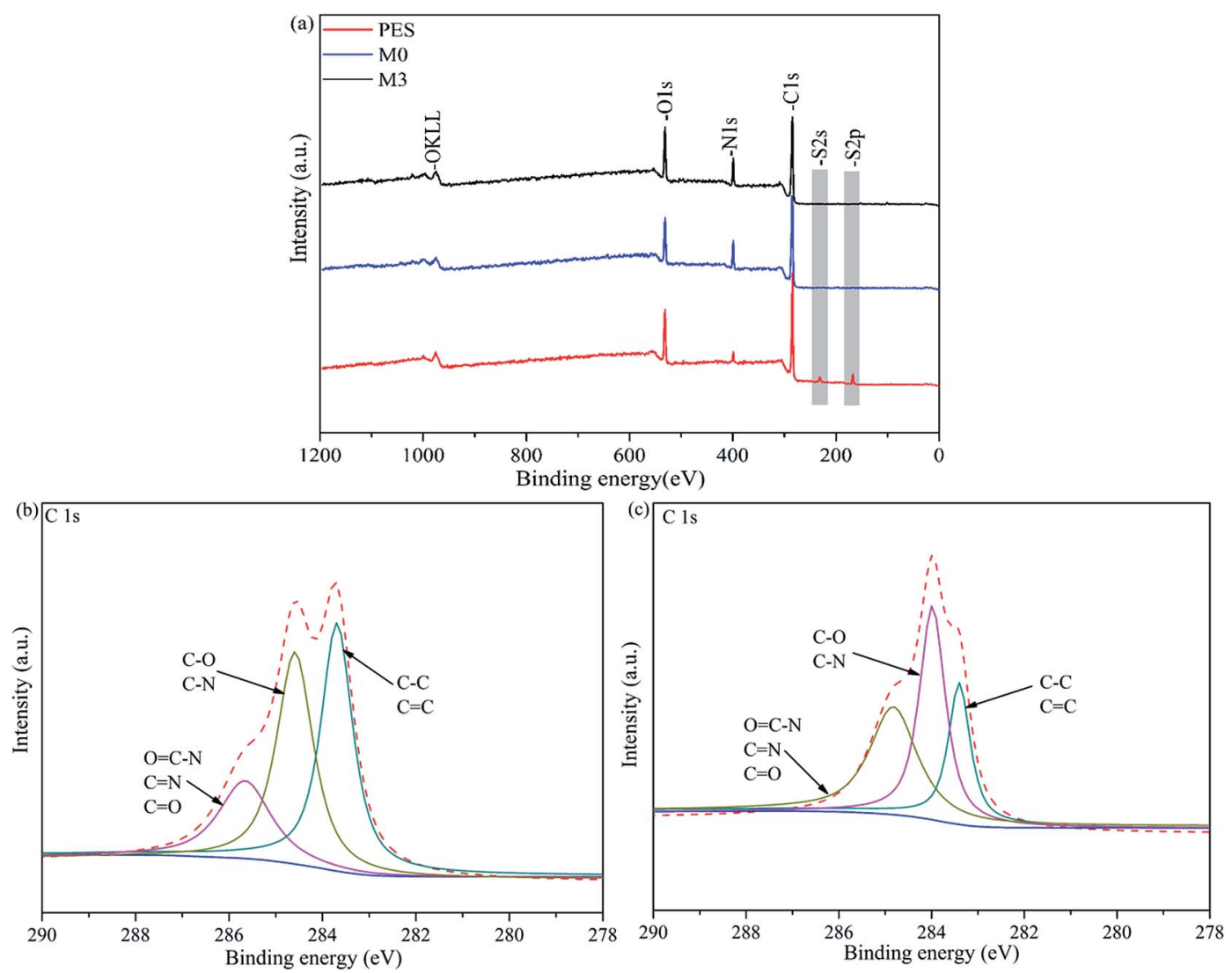

Fig. 5 (a) XPS wide scan substrate PES, MO, M3 nanofiltration membrane; comparison of high-resolution XPS C 1s spectrum for (b) MO and (c) M3. 
groups of GO in aqueous solution would react with PIP and TMC during the IP process, and formed some amide linkages. ${ }^{51}$ Moreover, the new peak at around $3320 \mathrm{~cm}^{-1}$ was appeared in M3 membrane, which was the hydroxyl stretching vibration. These information demonstrated that the GO was successfully introduced into the PPA/GO selective layer and potentially enhanced the hydrophilicity of membrane surface. ${ }^{52,53}$ This conclusion would be proved by the subsequent contact angle measurement.

To further verify the selective layer of PPA/GO membrane surface was successfully modified with GO, XPS was applied to investigate the different elemental compositions between M0 and M3 membrane as shown in Fig. 5. In Fig. 5(a), the C and O elements signal of XPS peaks both appeared in the spectra of $\mathrm{M} 0$ and M3. The S signal intensity of M0 and M3 decreased, while the $\mathrm{N}$ signal intensity of $\mathrm{M} 0$ and $\mathrm{M} 3$ increased as compared with PES substrate, indicating an ultrathin polyamide active skin layer was formed. Compared with M0, as the GO nanosheets contained numerous oxygen and carbon elements, the M3 membrane had a higher proportion of oxygen and carbon (Table 4). Fig. 5(b) and (c) showed the high resolution $\mathrm{C}$ 1s spectra. The peak area percentage of $\mathrm{C}-\mathrm{O}$ and $\mathrm{C}=\mathrm{O}$ bonds increased from $\mathrm{M} 0$ to $\mathrm{M} 3$ due to abundant $\mathrm{C}-\mathrm{O}$ and $\mathrm{C}=\mathrm{O}$ bonds in GO. The higher percentage of carbon, oxygen element and $\mathrm{C}-\mathrm{O}$ bond on the surface of M3 suggested that the PPA active layer had been modified by GO nanosheets.

The surface charge of the PPA/GO composite NF membranes were studied by measuring streaming potential with $\mathrm{pH}$ values 3.0-11.0. Fig. 6 showed the surface zeta potentials of M0, M1, M2, M3 and M4. It could be observed that all the membranes surface negative charge increased with increasing of $\mathrm{pH}$ values. The negative charge on membrane surface was largely ascribed to the carboxyl groups (-COO-), which was the unreacted acyl chloride $(-\mathrm{COCl})$ hydrolyzed in water. ${ }^{54}$ Moreover, the PPA/GO composite NF membranes had nearly the same zeta potential at $\mathrm{pH}=7.0$, so they should have the same salts rejection for multivalent ion. This conclusion was later demonstrated by the membrane performance for salts rejection.

\subsection{Surface hydrophilicity}

The water contact angles measured for PES substrate and PPA/ GO membranes were shown in Fig. 7. The average contact angle results for the PES, M0, M1, M2, M3 and M4 membranes were $69^{\circ} \pm 3.3^{\circ}, 62^{\circ} \pm 2.3^{\circ}, 60 \pm 1.2^{\circ}, 58^{\circ} \pm 1.8^{\circ}, 51^{\circ} \pm 1.5^{\circ}$ and $42^{\circ} \pm$ $1.4^{\circ}$ respectively. Compared with the PES substrate, M0 had a lower contact angle, which was attributed to the amide bonds. ${ }^{55}$ Apart from the amide bonds improving the surface

Table 4 XPS analysis results of the atomic concentration of MO and M3 membrane

\begin{tabular}{lrrr}
\hline Membrane ID & C (\%) & N (\%) & O (\%) \\
\hline M0 & 73.01 & 11.11 & 15.88 \\
M3 & 76.79 & 3.99 & 19.22
\end{tabular}

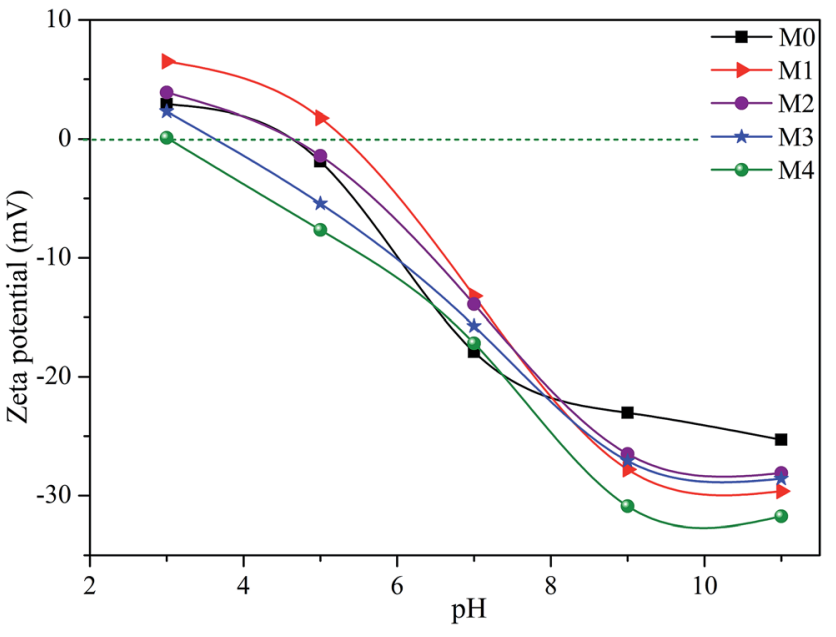

Fig. 6 Surface zeta potential as function of $\mathrm{pH}$ for M0-M4 membranes.

hydrophilicity, the PPA/GO membrane surface were hydrolyzed into carboxyl groups during immersion in water. ${ }^{54}$ Moreover, with the increase of the hydrophilicity of the membrane (M1M4) surface assisted by oxygen-containing functional groups in GO nanosheets, the water contact angles of the membranes decreased with the increase of GO concentration. It proved again that the active layer of PPA/GO membrane surface had been successfully modified by the GO nanosheets. The improved hydrophilicity of the PPA/GO membrane would have greater water flux, ${ }^{39,49,50}$ which was in consistent with the later water filtration test.

\subsection{Effect of GO concentration for membrane performance}

The effect of GO concentration on the separation performance of NF membrane was investigated. As shown in Fig. 8, the water flux increased significantly with increasing GO contents. The salts rejection was almost independent of the GO concentration until it reached $300 \mathrm{mg} \mathrm{L}^{-1}$ and then decreased slightly. The increase of water flux with the increase of GO contents was

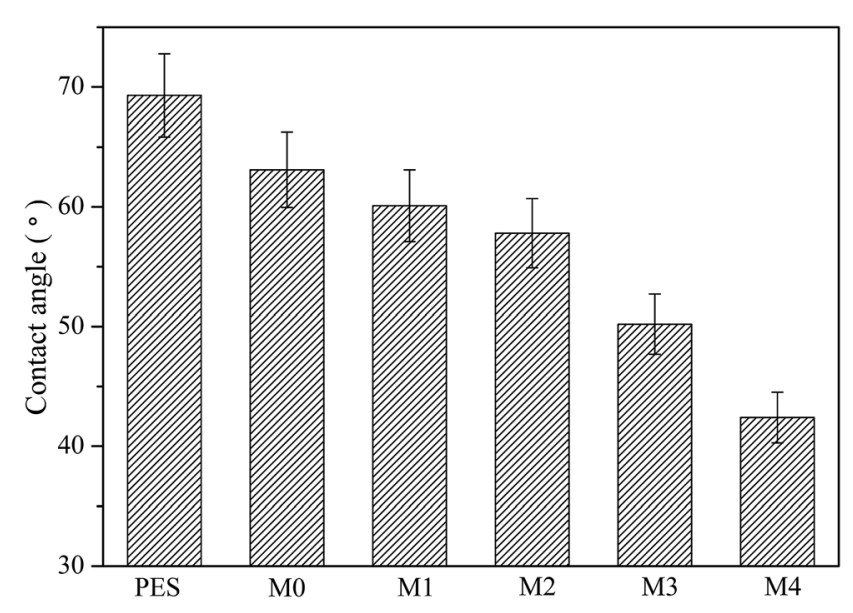

Fig. 7 Contact angles of the PES substrate and MO-M4 membranes. 


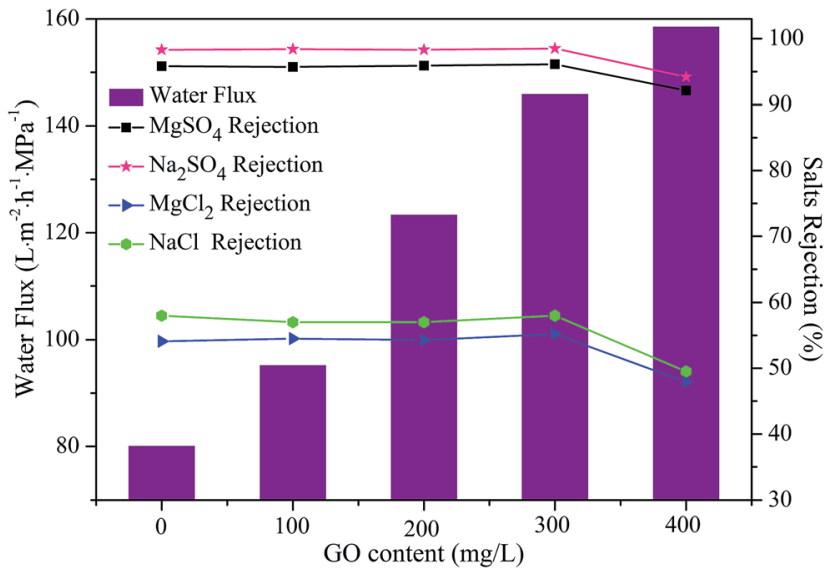

Fig. 8 Permeation properties of PPA/GO membranes (MO-M4) with different GO concentration.

mainly ascribed to the improvement of membrane surface hydrophilicity (as demonstrated in Fig. 7) by incorporating GO. ${ }^{56}$ The more hydrophilic of PPA/GO membranes surface, the more water molecules were attracted and permitted to pass through the membrane. ${ }^{57}$ Apart from the key factor, the other reasons could also help to improve the water flux such as the increased membrane free volume due to the mobilization of GO nanosheets in PPA/GO membrane disrupted polymer chain packing, ${ }^{49}$ the slightly increased mean effective pore size. This results were corresponding with the other reports. ${ }^{10,49,57,58}$ However, it should be noted that continuous increase in GO concentration led to slightly decrease of salts rejection, which could be ascribed to the aggregation of GO at higher loading. The similar behaviors were observed in previous works..$^{50,59}$

Morphological structure of the resultant PES, M0 and M3 composite membranes were observed by SEM and AFM, respectively. The SEM surface images of the PES UF substrate, M0 and M3 membranes were provided in Fig. 9(a)-(c). The distinct "leaf-like" folds and reticular active layer could be clearly seen after the interfacial polymerization from Fig. 9(b) and (c).

The SEM cross-section images of the PES UF substrate, M0 and M3 membranes were shown in Fig. 9(d) and (e). Fig. 9(d) illustrated the UF membrane's asymmetric structure. Fig. 9(e) and (f) demonstrated that the PPA/GO membrane had a composite structure that consist of a thin active layer and a fingerlike micro-voids transition layer. Fig. $9(\mathrm{~g})$ and (h) showed the magnification thin layer of M0 and M3, which was estimated about $120 \mathrm{~nm}$ and $136 \mathrm{~nm}$ thick, respectively.

Fig. 10 showed the two and three-dimensional AFM surface topography of the PES and PPA/GO membranes. The root average arithmetic roughness $\left(R_{\mathrm{a}}\right)$, root mean surface roughness

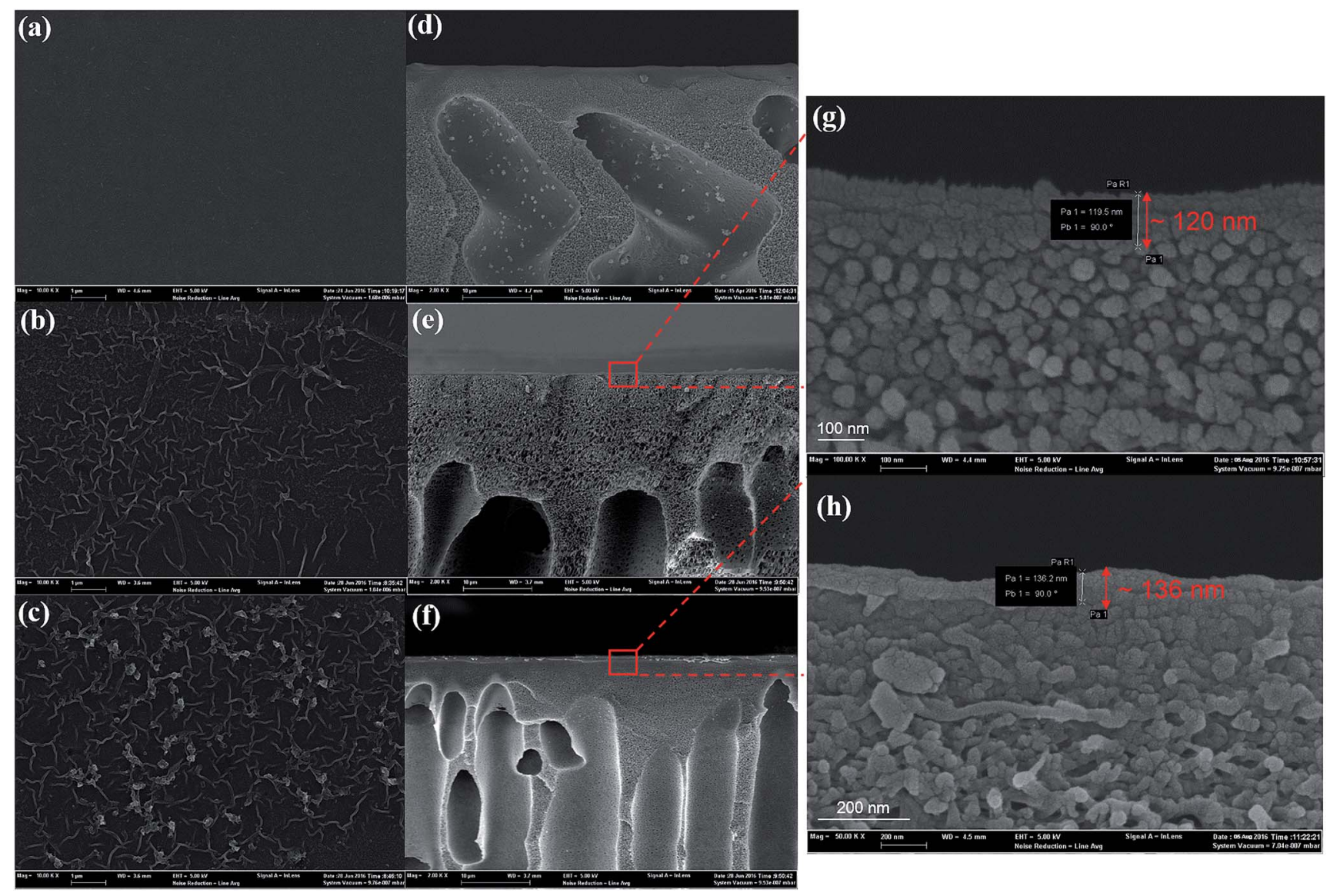

Fig. 9 SEM surface images of (a) PES substrate, (b) MO, (c) M3. Cross-section images of (d) PES substrate, (e) M0, (f) M3 membrane and magnification active layer of $\mathrm{MO}(\mathrm{g})$ and $\mathrm{M} 3(\mathrm{~h})$. 

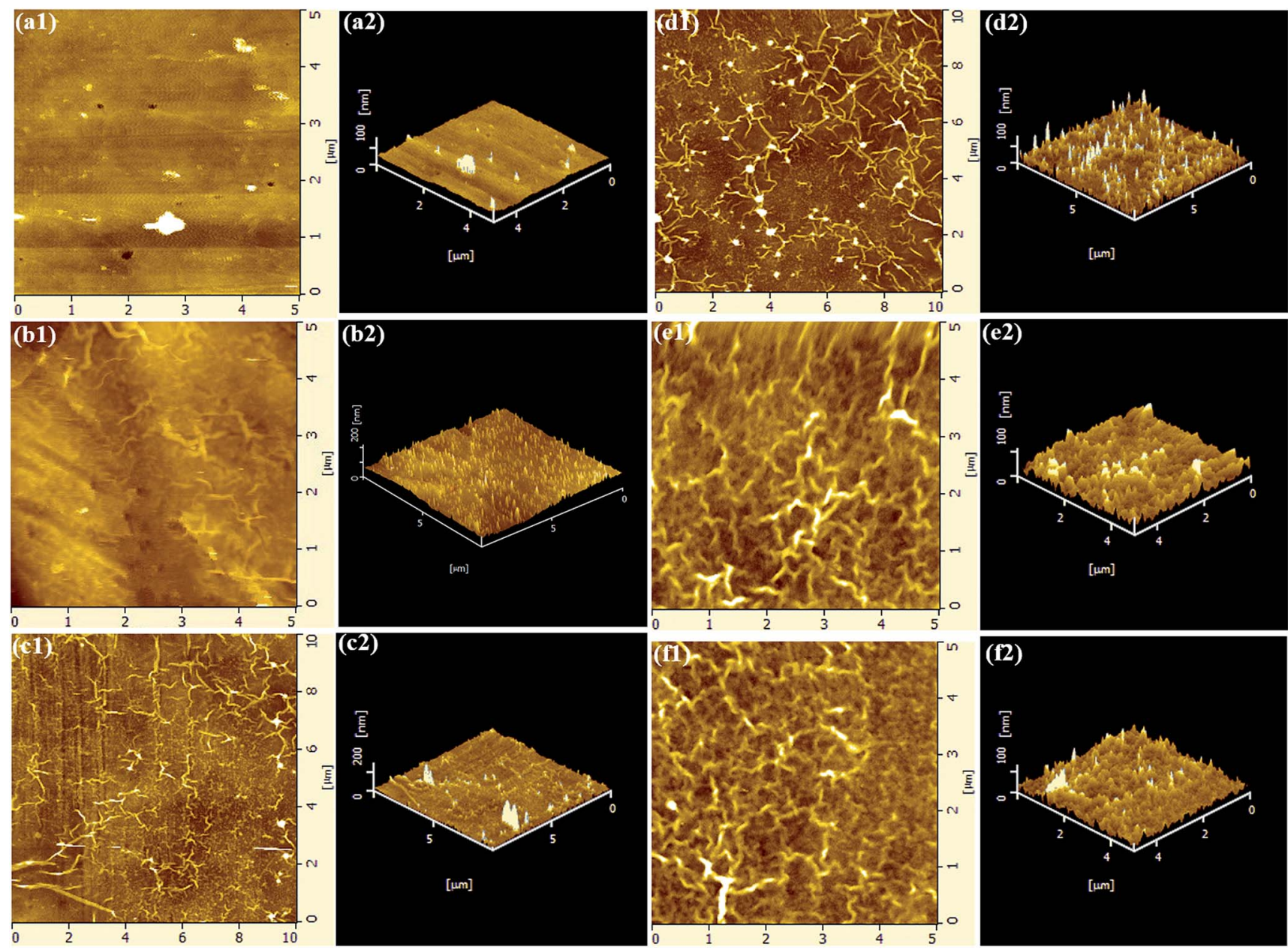

Fig. 10 Two- and three-dimensional AFM surface topography of PES substrate (a1 and a2); M0 (b1 and b2); M1 (c1 and c2); M2 (d1 and d2); M3 (e1 and $\mathrm{e} 2$ ) and M4 (f1 and f2).

$\left(R_{\mathrm{q}}\right)$ and root peak to valley $\left(R_{\max }\right)$ values of PES and PPA/GO membranes surface were estimated from AFM images, which were listed in Table 5. It should be noted that the $R_{\mathrm{q}}$ value increased from PES to M0 when IP reaction formed polyamide layer, while the $R_{\mathrm{q}}$ values of the PPA/GO membranes decreased with the increasing of GO contents. This meant that PPA/GO membrane surface became smoother, which was ascribed to the more distinct "leaf-like" folds (as observed in Fig. 9) by incorporation of GO during the IP process. ${ }^{49,60}$ The smoother membrane surface was an advantage for anti-fouling. ${ }^{58}$

Table 5 Root average arithmetic roughness $\left(R_{\mathrm{a}}\right)$, root mean surface roughness $\left(R_{\mathrm{q}}\right)$ and root peak to valley $\left(R_{\max }\right)$ values of PES and PPA/ GO membrane

\begin{tabular}{lccc}
$\begin{array}{l}\text { Membrane } \\
\text { ID }\end{array}$ & $R_{\mathrm{a}}(\mathrm{nm})$ & $R_{\mathrm{q}}(\mathrm{nm})$ & $R_{\max }(\mathrm{nm})$ \\
\hline PES & 4.87 & 8.59 & 163.4 \\
M0 & 17.26 & 23.15 & 270.7 \\
M1 & 11.78 & 18.91 & 256.4 \\
M2 & 10.83 & 15.23 & 163.8 \\
M3 & 10.09 & 12.48 & 130.8 \\
M4 & 9.82 & 11.65 & 114.4
\end{tabular}

\subsection{The performance of the PPA/GO membrane}

The salts rejection characteristics of M0 and M3 composite NF membranes were investigated by dissolving $\mathrm{Na}_{2} \mathrm{SO}_{4}, \mathrm{MgSO}_{4}$, $\mathrm{NaCl}$ and $\mathrm{MgCl}_{2}$ in DI water at a concentration of $2000 \mathrm{mg} \mathrm{L}^{-1}$ as shown in Fig. 11. The curve of water flux indicated that M3 membrane exhibited a higher pure water flux of $146\left(\mathrm{~L} \mathrm{~m}^{-2} \mathrm{~h}^{-1}\right.$ $\mathrm{MPa}^{-1}$ ) and still maintained higher salts rejection compared with M0 membrane. As for M3 membrane, higher hydrophilicity and lower roughness membrane surface were generally deemed to improve the water flux observed in Fig. 11.

The rejection performances of salts solution shown in Fig. 11 suggested that M0 membrane exhibited different rejections to salts in order of $\mathrm{Na}_{2} \mathrm{SO}_{4}(98.2 \%)>\mathrm{MgSO}_{4}(96.5 \%)>\mathrm{NaCl}$ $(56.8 \%)>\mathrm{MgCl}_{2}(50.5 \%)$, which was corresponding with the negatively charged membrane characteristics. The different salts rejection of NF membrane were based on both the membrane pore size and the Donnan electrostatic exclusion between the membrane and charged ions in solution. ${ }^{61,62}$ The surface of the PPA/GO membranes surface were negatively charged at $\mathrm{pH}=7.0$ (as demonstrated in Fig. 6). Thus the result of salts rejection was corresponding with the Donnan electrostatic exclusion effects. ${ }^{1}$ In particular, the negative charge of NF 

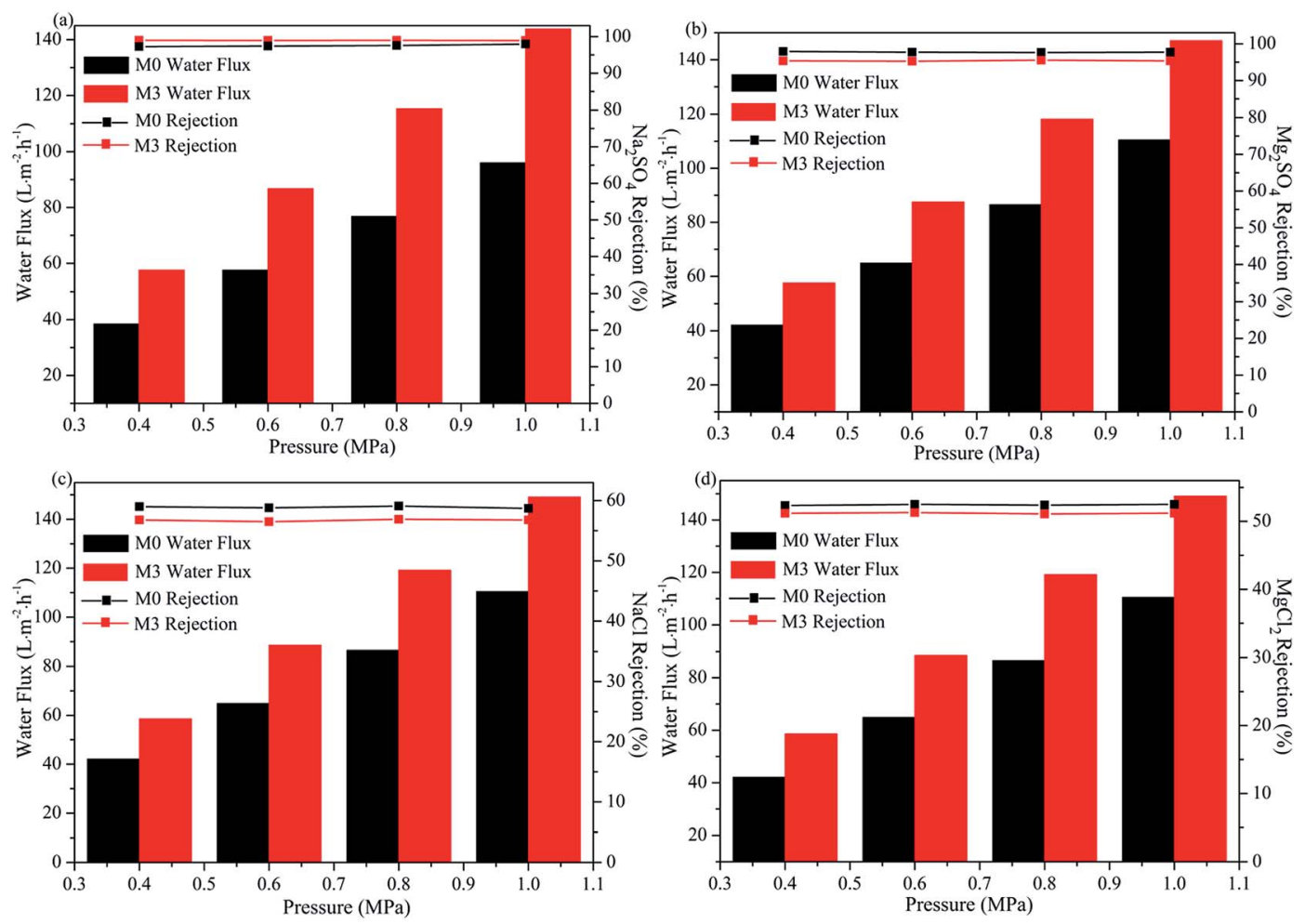

Fig. 11 Permeation and rejection properties of MO and M3 membrane to different salts.

membrane surface showed a stronger electrostatic exclusion effect on $\mathrm{SO}_{4}{ }^{2-}$ than on $\mathrm{Cl}^{-}$. However, based on the rule of Donnan electrostatic exclusion mechanism, the rejection of $\mathrm{NF}$ membrane to these $1: 1$ type inorganic salts $\left(\right.$ e.g. $\mathrm{MgSO}_{4}$ and $\mathrm{NaCl}$ ) should be equal. This abnormal phenomenon was ascribed to a higher diffusivities of the monovalent ions than that of the bivalent ions, ${ }^{63}$ thus the rejection of $\mathrm{NaCl}$ was lower than that of $\mathrm{MgSO}_{4}$. Additionally, a higher rejection of $\mathrm{NaCl}$ than $\mathrm{MgCl}_{2}$ could be observed in Fig. 11(c) and (d), which was attributed to a higher positive charge of $\mathrm{Mg}^{2+}$ than $\mathrm{Na}^{+}$, and led to stronger shielding effect. ${ }^{43}$

Further, it could be found that the salts rejection of M3 membrane decreased slightly after incorporating GO nanosheets. Similar observation had been reported in the literature. ${ }^{49,60}$ This phenomenon could be interpreted by the different particle size of GO sheets that possibility affected the integrity of PPA active layer. ${ }^{60}$ Moreover, it should be noticed that although M3 membrane had slightly lower surface zeta potential at $\mathrm{pH}=$ 7.0 than M0 membrane (as demonstrated in Fig. 6), a small decrease in the salts rejection of M3 membrane revealed that the separation performance of PPA/GO membranes was unacted on the GO nanosheets. ${ }^{49}$

\subsection{The molecular weight cut-off, mean effective pore size and pore size distribution of PPA/GO membrane}

The solutes rejection and pore size distribution of M0, M3 membrane were shown in Fig. 12, respectively. MWCO referred to a molecular weight of solute molecule, $90 \%$ of which was rejected by membranes. It was calculated by Fig. 12(a) and eqn
(6). The mean effective pore size $\left(\mu_{\mathrm{p}}\right)$, geometric standard deviation $\left(\sigma_{\mathrm{p}}\right)$ and MWCO of M0, M3 were measured and listed in Table 6. It indicated that the mean effective pore size and MWCO of M3 membrane increased by incorporating GO, which in turn would improve the water flux. The mean effective pore size and MWCO of M3 membrane were approximate $0.53 \mathrm{~nm}$ and $1059 \mathrm{Da}$, respectively.

\subsection{Anti-fouling property of the PPA/GO membrane}

The $200 \mathrm{mg} \mathrm{L}^{-1} \mathrm{HA}$ with $20 \mathrm{mg} \mathrm{L}^{-1}$ calcium chloride and $200 \mathrm{mg}$ $\mathrm{L}^{-1}$ BSA aqueous solutions were used to appraise the anti-fouling property of the prepared M0 and M3 membranes. In this fouling experiments, all the membranes were tested at the same initial water flux $\left(J_{0}\right)$ of $100\left(\mathrm{~L} \mathrm{~m}^{-2} \mathrm{~h}^{-1} \mathrm{MPa}^{-1}\right)$ to eliminate the impact of trans-membrane hydrodynamic force on the anti-fouling test. ${ }^{64}$ Fig. 13 displayed the normalized flux $\left(J / J_{0}\right)$ of M0 and M3 membranes in the BSA and HA aqueous solutions, respectively.

It was observed from Fig. 13, with the filtration time prolongs, the water fluxes of M3 membrane decreased rapidlyto-slowly due to the deposition of foulant molecules on the membrane surface before filtration of $12 \mathrm{~h}$ and then kept constant after filtration of $12 \mathrm{~h}$. The fluxes becoming stable meant that the adsorption and desorption of foulants reached an equilibrium on the membrane surface. ${ }^{65,66}$ For M0 membrane, the decline ratios of the water flux to HA and BSA solutions were $49.5 \%$ and $28.9 \%$, respectively. However, in terms of M3 membrane, it was less than $10.5 \%$ and $5.0 \%$, respectively. The lower flux decline ratio of $\mathrm{M} 3$ illustrated that M3 membrane had better anti-fouling property than the 

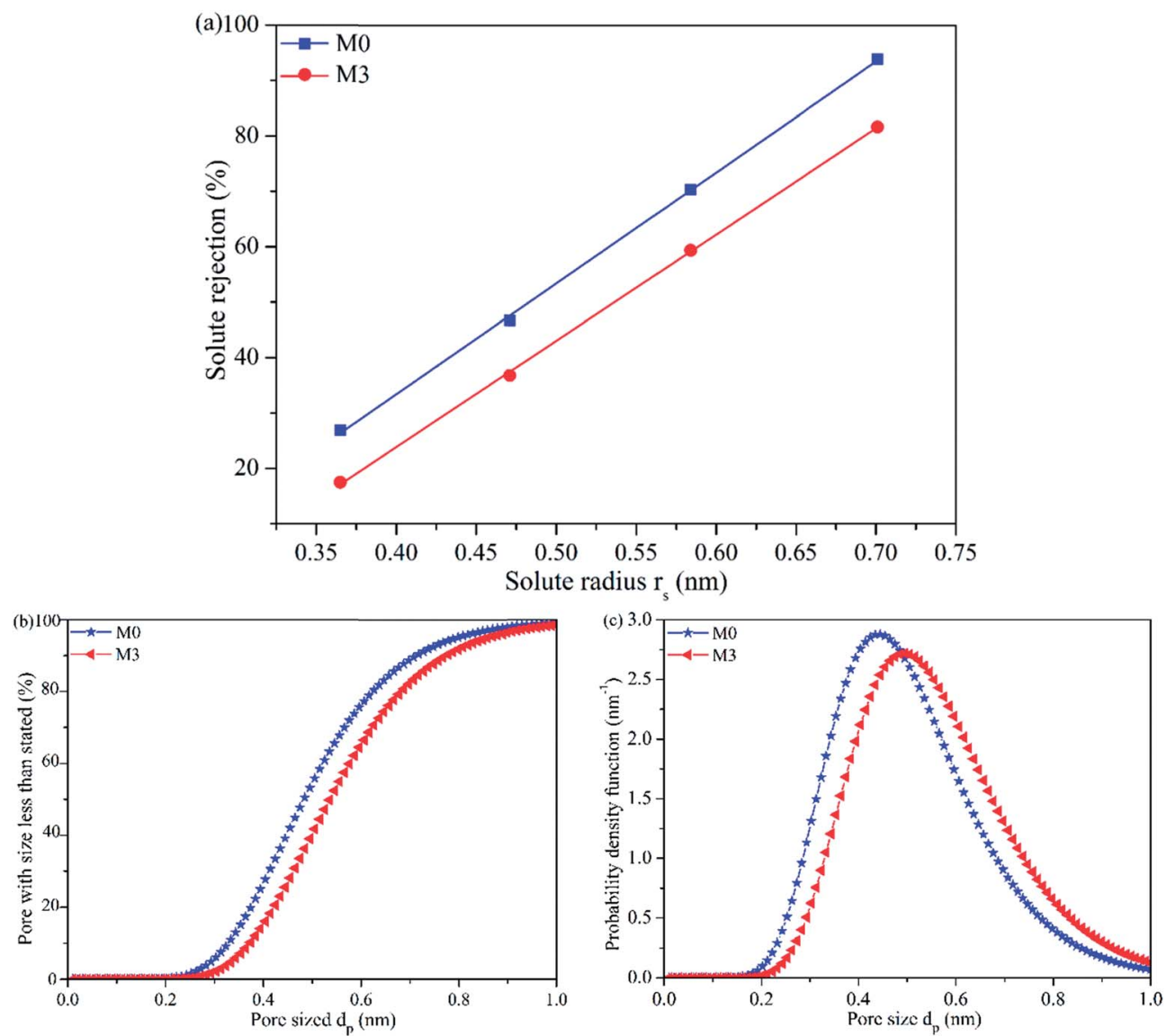

Fig. 12 (a) Rejection curve of solute rejection against Stokes radius. (b) Cumulative pore size distribution and (c) probability density function curve of MO, M3 membrane.

Table 6 Mean effective pore size $\left(\mu_{\mathrm{p}}\right)$, geometric standard deviation $\left(\sigma_{\mathrm{p}}\right)$ and $\mathrm{MWCO}$ of $\mathrm{MO}, \mathrm{M3}$

\begin{tabular}{llll}
\hline Membrane ID & $\mu_{\mathrm{p}}(\mathrm{nm})$ & $\sigma_{\mathrm{p}}$ & MWCO (Da) \\
\hline M0 & 0.45 & 1.35 & 850 \\
M3 & 0.53 & 1.33 & 1059 \\
\hline
\end{tabular}

pristine M0 membrane. It implied that the modified PPA active layer with GO nanosheets improved the anti-fouling property, which was attributed to a higher hydrophilicity of membrane surface stemming from GO nanosheets such as carboxyl and hydroxyl hydrophilic groups. ${ }^{52}$ Thus, a thin water layer may be formed between the hydrophilic surface and water solution via hydrogen bonds, ${ }^{10}$ and largely helped to retard the absorption of hydrophobic pollutants on the membrane surface and reduce the membrane fouling. ${ }^{67,68}$ Moreover, a smoother of M3 membrane surface (Table 5) could also contribute to improve the anti-fouling property. ${ }^{58}$ Therefore, hydrophobic model foulants BSA and HA could be adsorbed more easily on the surface of the relatively hydrophobic and rough M0 membrane than M3 membrane. Hence, it was verified that the anti-fouling property of the PPA/GO membranes were enhanced through increasing the hydrophilic character assisted by hydrophilic GO nanosheets.

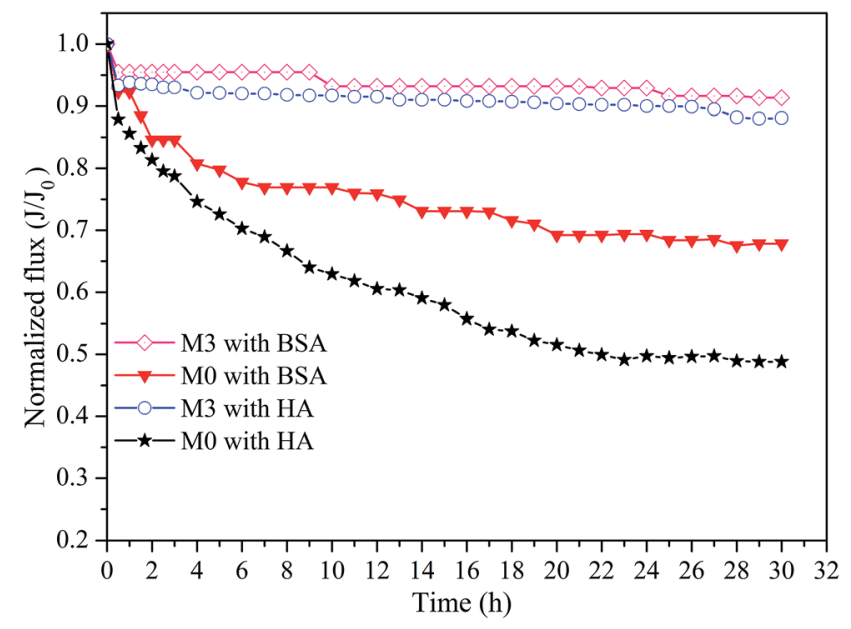

Fig. 13 Characterization of MO and M3 membrane anti-fouling with $\mathrm{HA}$ and BSA.

\section{Conclusion}

A novel high water flux and anti-fouling PPA/GO composite nanofiltration membrane was successfully fabricated by IP in this work, using the uniform aqueous of PIP/GO (the GO 
loadings varied from 0 to $400 \mathrm{mg} \mathrm{L}^{-1}$ ) and TMC organic solutions as the two phase monomers solutions on a polyether sulfone substrates. The hydrophilicity of GO nanosheets was incorporated into the PPA active layer, which was confirmed by the ATR-FTIR and XPS results. The hydrophilicity of membrane surface increased and roughness decreased. The water flux of M3 (300 mg L $\left.{ }^{-1} \mathrm{GO}\right)$ membrane increased from $66\left(\mathrm{~L} \mathrm{~m}^{-2} \mathrm{~h}^{-1}\right)$ to $87.6\left(\mathrm{~L} \mathrm{~m}^{-2} \mathrm{~h}^{-1}\right)$ under the operating pressure of $0.6 \mathrm{MPa}$, while the high salts rejection still maintained. The PPA/GO membranes also showed an excellent anti-fouling ability to BSA and HA solutions. These test results suggested that the polyamide composite nanofiltration could be effectively modified by hydrophilicity GO nano-materials at a low loading for high water permeation, good salts rejection and excellent antifouling property, which could make the membrane separation process efficient and endurable in water purification.

\section{Acknowledgements}

The authors greatly appreciate the financial supports of Jiangsu National Synergetic Innovation Center for Advanced Materials (SICAM), National Natural Science Foundation of China (21576150, 21476245), Science Foundation of Tsinghua University (20131089399) and the Special funds for technological development research of Research Institutes from National Ministry of Science and Technology (2013EG111129).

\section{References}

1 M. Mulder, Basic Principles of Membrane Technology, Kluwer Academic Publishers, 1996.

2 R. Rautenbach and A. Gröschl, Desalination, 1990, 77, 73-84. 3 J. Luo and Y. Wan, J. Membr. Sci., 2011, 372, 145-153.

4 Y. Lu and J. Chen, Ind. Eng. Chem. Res., 2011, 50, 7345-7354. 5 S. Yu, Z. Chen, Q. Cheng, Z. Lü, M. Liu and C. Gao, Sep. Purif. Technol., 2012, 88, 121-129.

6 Š. Schlosser, R. Kertész and J. Marták, Sep. Purif. Technol., 2005, 41, 237-266.

7 J. Cadotte, K. Cobian, R. Forester and R. Petersen, Continued Evaluation of In situ-formed Condensation Polymers for Reverse Osmosis Membranes, NTIS Report No. PB-253193, 1976.

8 J. E. Cadotte, M. J. Steuck and R. J. Petersen, Research on In situ-formed Condensation Polymers for Reverse Osmosis Membranes, NTIS Report No. PB-288387, 1978.

9 R. J. Petersen, J. Membr. Sci., 1993, 83, 81-150.

10 S. Xia, L. Yao, Y. Zhao, N. Li and Y. Zheng, Chem. Eng. J., 2015, 280, 720-727.

11 M. Safarpour, A. Khataee and V. Vatanpour, Ind. Eng. Chem. Res., 2014, 140819070522009, DOI: 10.1021/ie502407g.

12 D. Rana and T. Matsuura, Chem. Rev., 2010, 110, 2448-2471.

13 F. Liu, Y.-Y. Xu, B.-K. Zhu, F. Zhang and L.-P. Zhu, J. Membr. Sci., 2009, 345, 331-339.

14 L. Yan, Y. S. Li, C. B. Xiang and S. Xianda, J. Membr. Sci., 2006, 276, 162-167.
15 V. Vatanpour, S. S. Madaeni, A. R. Khataee, E. Salehi, S. Zinadini and H. A. Monfared, Desalination, 2012, 292, 19-29.

16 N. A. Hashim, Y. Liu and K. Li, Ind. Eng. Chem. Res., 2011, 50, 3035-3040.

17 X. Wang, C. Chen, H. Liu and J. Ma, Water Res., 2008, 42, 4656-4664.

18 M. J. Han, G. N. B. Baroña and B. Jung, Desalination, 2011, 270, 76-83.

19 Y. Chang, C.-Y. Ko, Y.-J. Shih, D. Quémener, A. Deratani, T.-C. Wei, D.-M. Wang and J.-Y. Lai, J. Membr. Sci., 2009, 345, 160-169.

20 B. Deng, M. Yu, X. Yang, B. Zhang, L. Li, L. Xie, J. Li and X. Lu, J. Membr. Sci., 2010, 350, 252-258.

21 A. Rahimpour, S. S. Madaeni, S. Zereshki and Y. Mansourpanah, Appl. Surf. Sci., 2009, 255, 7455-7461.

22 G. Wu, S. Gan, L. Cui and Y. Xu, Appl. Surf. Sci., 2008, 254, 7080-7086.

23 B. J. Hinds, N. Chopra, T. Rantell, R. Andrews, V. Gavalas and L. G. Bachas, Science, 2004, 303, 62-65.

24 P. Aerts, S. Kuypers, I. Genne, R. Leysen, J. Mewis, I. F. Vankelecom and P. A. Jacobs, J. Phys. Chem. B, 2006, 110, 7425-7430.

25 S.-R. Chae, S. Wang, Z. D. Hendren, M. R. Wiesner, Y. Watanabe and C. K. Gunsch, J. Membr. Sci., 2009, 329, 68-74.

26 B.-H. Jeong, E. M. V. Hoek, Y. Yan, A. Subramani, X. Huang, G. Hurwitz, A. K. Ghosh and A. Jawor, J. Membr. Sci., 2007, 294, 1-7.

27 S. Y. Lee, H. J. Kim, R. Patel, S. J. Im, J. H. Kim and B. R. Min, Polym. Adv. Technol., 2007, 18, 562-568.

$28 \mathrm{~J}$. D. Schiffman and M. Elimelech, ACS Appl. Mater. Interfaces, 2011, 3, 462-468.

29 J. S. Taurozzi, H. Arul, V. Z. Bosak, A. F. Burban, T. C. Voice, M. L. Bruening and V. V. Tarabara, J. Membr. Sci., 2008, 325, 58-68.

30 Y. Wang, S. Chen, L. Qiu, K. Wang, H. Wang, G. P. Simon and D. Li, Adv. Funct. Mater., 2015, 25, 126-133.

31 K. Zodrow, L. Brunet, S. Mahendra, D. Li, A. Zhang, Q. Li and P. J. J. Alvarez, Water Res., 2009, 43, 715-723.

32 K. Hu, M. K. Gupta, D. D. Kulkarni and V. V. Tsukruk, Adv. Mater., 2013, 25, 2301-2307.

33 X. Zhao, Q. Zhang, Y. Hao, Y. Li, Y. Fang and D. Chen, Macromolecules, 2010, 43, 9411-9416.

34 J. Liang, Y. Huang, L. Zhang, Y. Wang, Y. Ma, T. Guo and Y. Chen, Adv. Funct. Mater., 2009, 19, 2297-2302.

35 M. Koinuma, C. Ogata, Y. Kamei, K. Hatakeyama, H. Tateishi, Y. Watanabe, T. Taniguchi, K. Gezuhara, S. Hayami, A. Funatsu, M. Sakata, Y. Kuwahara, S. Kurihara and Y. Matsumoto, J. Phys. Chem. C, 2012, 116, 19822-19827.

36 H. Li and C. Bubeck, Macromol. Res., 2013, 21, 290-297.

37 J. Zhang, Z. Xu, W. Mai, C. Min, B. Zhou, M. Shan, Y. Li, C. Yang, Z. Wang and X. Qian, J. Mater. Chem., 2013, 1, 3101.

38 J. Lee, H.-R. Chae, Y. J. Won, K. Lee, C.-H. Lee, H. H. Lee, I.-C. Kim and J.-m. Lee, J. Membr. Sci., 2013, 448, 223-230. 
39 N. Wang, S. Ji, G. Zhang, J. Li and L. Wang, Chem. Eng. J., 2012, 213, 318-329.

40 X.-L. Wang, T. Tsuru, S.-i. Nakao and S. Kimura, J. Membr. Sci., 1997, 135, 19-32.

41 A. S. Michaels, Sep. Sci. Technol., 1980, 15, 1305-1322.

42 S. Singh, K. C. Khulbe, T. Matsuura and P. Ramamurthy, J. Membr. Sci., 1998, 142, 111-127.

43 T. Wang, C. Zhao, P. Li, Y. Li and J. Wang, J. Membr. Sci., 2015, 477, 74-85.

44 W. R. Bowen and A. W. Mohammad, Chem. Eng. Res. Des., 1998, 76, 885-893.

45 S. Zhang, Y. Zhang and T.-S. Chung, ACS Sustainable Chem. Eng., 2016, 4, 1154-1160.

46 M. Kumar, Z. Gholamvand, A. Morrissey, K. Nolan, M. Ulbricht and J. Lawler, J. Membr. Sci., 2016, 506, 38-49.

47 X. Zhao, H. Xuan and C. He, RSC Adv., 2015, 5, 81115-81122. 48 Y. Li, Y. Su, X. Zhao, R. Zhang, Y. Liu, X. Fan, J. Zhu, Y. Ma, Y. Liu and Z. Jiang, Ind. Eng. Chem. Res., 2015, 54, 8302-8310.

49 S. Bano, A. Mahmood, S.-J. Kim and K.-H. Lee, J. Mater. Chem. A, 2015, 3, 2065-2071.

50 M. Hu and B. Mi, Environ. Sci. Technol., 2013, 47, 3715-3723.

51 N. K. Saha and S. V. Joshi, J. Membr. Sci., 2009, 342, 60-69.

52 Z. Wang, H. Yu, J. Xia, F. Zhang, F. Li, Y. Xia and Y. Li, Desalination, 2012, 299, 50-54.

53 C. Zhao, X. Xu, J. Chen and F. Yang, J. Environ. Chem. Eng., 2013, 1, 349-354.
54 F. Yang, S. Zhang, D. Yang and X. Jian, J. Membr. Sci., 2007, 301, 85-92.

55 K. S. Lee, Eur. J. Hist. Econ. Thought, 2011, 18, 755-776.

56 G. N. B. Baroña, J. Lim, M. Choi and B. Jung, Desalination, 2013, 325, 138-147.

57 H. M. Hegab and L. Zou, J. Membr. Sci., 2015, 484, 95-106.

58 H.-R. Chae, J. Lee, C.-H. Lee, I.-C. Kim and P.-K. Park, J. Membr. Sci., 2015, 483, 128-135.

59 E. S. Kim and B. L. Deng, J. Membr. Sci., 2011, 375, 46-54.

60 J. Yin, G. Zhu and B. Deng, Desalination, 2016, 379, 93-101.

61 J. M. M. Peeters, J. P. Boom, M. H. V. Mulder and H. Strathmann, J. Membr. Sci., 1998, 145, 199-209.

62 J. Schaep, B. Van der Bruggen, C. Vandecasteele and D. Wilms, Sep. Purif. Technol., 1998, 14, 155-162.

63 N. F. D. Aba, J. Y. Chong, B. Wang, C. Mattevi and K. Li, J. Membr. Sci., 2015, 484, 87-94.

64 C. Zhou, Y. Shi, C. Sun, S. Yu, M. Liu and C. Gao, J. Membr. Sci., 2014, 471, 381-391.

65 T. Ma, Y. Su, Y. Li, R. Zhang, Y. Liu, M. He, Y. Li, N. Dong, H. Wu and Z. Jiang, J. Membr. Sci., 2016, 503, 101-109.

66 Y. Li, Y. Su, X. Zhao, X. He, R. Zhang, J. Zhao, X. Fan and Z. Jiang, ACS Appl. Mater. Interfaces, 2014, 6, 5548-5557.

67 L. L. Hwang, J. C. Chen and M. Y. Wey, Desalination, 2013, 313, 166-175.

68 X. Li, J. Huang, Y. Zhang, Y. Lv, Z. Liu and Z. Shu, Desalin. Water Treat., 2015, 57, 10980-10987. 